See discussions, stats, and author profiles for this publication at: https://www.researchgate.net/publication/323666304

\title{
Horizontal target strength-size conversion equations for sea bass and gilt- head bream
}

Article in Aquaculture · January 2018

DOI: 10.1016/.jaquaculture.2018.02.034

CITATION

1

4 authors, including:

Vicky Rodríguez-Sánchez
Universidad de Sevilla

10 PUBLICATIONS 52 CITATIONS

SEE PROFILE
READS

149

Isabel Perez-Arjona

Universitat Politècnica de València

75 PUBliCATIONS 541 CITATIONS

SEE PROFILE

Some of the authors of this publication are also working on these related projects: 


\title{
Horizontal target strength-size conversion equations for sea bass and gilt-head bream
}

\author{
Victoria Rodríguez-Sánchez ${ }^{\mathrm{a},}$, Amadora Rodríguez-Ruiz ${ }^{\mathrm{a}}$, Isabel Pérez-Arjona ${ }^{\mathrm{b}}$, Lourdes Encina-Encina ${ }^{\mathrm{a}}$ \\ a Department of Plant Biology and Ecology, Faculty of Biology, University of Seville, PO Box 1095, E-41080 Seville, Spain \\ ${ }^{\mathrm{b}}$ Department of Applied Physics, Polytechnique University of Valecia, Spain
}

\section{A R T I C L E IN F O}

Keywords:

Hydroacoustic

Target-strength equation

Sea bass

Gilt-head bream

Aquaculture

\begin{abstract}
A B S T R A C T
Horizontal hydroacoustics is a technique of remote fish detection that has proved to efficiently determine fish density and biomass in shallow or superficial waters. This non-intrusive technique could render better results than those obtained by conventional sampling when monitoring shallow waters. To apply this technique, we need equations that relate the amount of sound returned by fish, known as target strength (TS in $\mathrm{dB}$ ), with their length $(\mathrm{mm})$ or weight $(\mathrm{g})$. This study presents horizontal conversion equations for the species gilt-head bream (Sparus aurata) and sea bass (Dicentrarchus labrax), two of the most important species bred in aquaculture. Moreover, this study presents a new formula to calculate a mixed equation adjusted to the percentage of distribution of those species in case of mixed populations. The results in this research have been obtained by applying a simple setup that allows for high-quality acoustic data. These new equations will enable the application of this technique in order to estimate these species' density and biomass in shallow aquatic systems such as aquaculture ponds with semi-intensive production densities.
\end{abstract}

\section{Introduction}

Nowadays, aquaculture as a whole produces more than half of all fish consumed in the world. In southern European countries, gilt-head bream (Sparus aurata) and sea bass (Dicentrarchus labrax) are the most produced and consumed species (Apromar, 2016).

Quantity and biomass estimations of fish in ponds are essential for preparing the production and management plan of aquaculture companies. For example, feeding constitutes $>50 \%$ of production costs (Soliveres, 2015). This feeding estimation is based on the biomass of the ponds together with other factors, such as average fish size, time of year, water temperature, etc. The accuracy of these estimates allows for an optimization of the feeding processes and minimizes waste products, which improves the quality of water. In addition, the use of techniques that provide us with accurate estimates improves population management plans. This includes splitting the ponds, i.e. distributing the fish group from one pond into two different ponds in order to facilitate their growth and development as well as population monitoring.

Nowadays, in order to estimate fish biomass in shallow aquaculture ponds, managers conduct periodic samplings that usually give wrong estimates. They calculate the number of fish present in a pond as an approximation that takes into account the initial number of sowed fish and countable deaths. Biomass is estimated by multiplying this number by the average weight of fish captured by manual methods (Conti et al., 2006). In addition to not being accurate enough, this type of manual sampling causes a high level of stress in fish, which sometimes leads to pathologies and sudden deaths. Furthermore, these methods can monitor fish in normal production conditions, but they are not valid in exceptional situations where losses cannot be quantified, for example in cases of theft, predators or extensive deaths. In these cases, traditional methods cannot determine the quantity of fish remaining in the pond.

The results presented in this study belong to an extended project aimed at estimating biomass in fish production systems using non-invasive methods (PI_57052). Given that hydroacoustics is one of the most relevant existing capture-independent methods, applying it to shallow ponds would considerably improve fish's wellbeing. Unlike visual methods, hydroacoustics is also efficient when used in systems with poor visibility (Lucas and Baras, 2000; Simmonds and Maclennan, 2005; Kubečka et al., 2009) such as production ponds. However, hydroacoustics does not work properly in cases of very high densities. Therefore, it could only be used in production ponds with extensive or semi-intensive farming. Another advantage of hydroacoustics is that it studies the aquatic system at the exact moment when sampling is being performed, taking an instant picture of the situation in the pond. Therefore, it would be useful even in the exceptional cases previously mentioned.

\footnotetext{
* Corresponding author.

Email address: vrodriguez@us.es (V. Rodríguez-Sánchez)
} 
Horizontal hydroacoustics is a technique where sound is used to study aquatic ecosystems. Acoustic instruments (the echosounder) transmit and receive sound waves used to detect fish and other objects beyond the water surface (Simmonds and MacLennan, 2005). The key to properly interpreting hydroacoustic data is the target strength value returned by fish (TS in $\mathrm{dB}$ re $1 \mathrm{~m}^{2}$ ). This value allows one to create conversion equations to translate the sound returned by fish (TS) into biological parameters that can be measured, such as length or weight. The use of these equations allows calculating the size and quantity of fish in an ecosystem (Lucas and Baras, 2000). Moreover, in horizontal applications, it has been proven that changes in TS are related to changes in the swimming direction of fish. Therefore, horizontal conversion equations need to be developed for the three main orientations: side, oblique and head/tail (Foote, 1980; Kubecka and Duncan, 1998; Hazen and Horne, 2003; Frouzova et al., 2005; Henderson et al., 2007; Kubilius and Ona, 2012; Rodríguez-Sánchez et al., 2015).

Despite the fact that some conversion equations already exist for several fish species (Burwen and Fleischman, 1998; Lilja et al., 2000; Frouzova et al., 2005; Boswell and Wilson, 2008; among others), these are not sufficient to meet the needs of hydroacoustics. General equations could be used to convert acoustic data. However, given that TS values are species-dependent, the results will be more accurate if species-specific equations are used when converting data. Consequently, this article is aimed at developing horizontal conversion equations for gilt-head bream (Sparus aurata) and European sea bass (Dicentrarchus labrax). Sometimes, ponds are composed by a mixture of these two species with known proportions. To calculate density and biomass in these situations, the equation of the species with a highest representation in the system is normally used. This paper also presents a simple method to create a mixed equation adapted to the percentage of these two species when surveying mixed ponds. All these equations will allow the application of this technique for routine estimations of density and biomass in shallow waters such as aquaculture ponds.

\section{Material and methods}

\subsection{Experimental set-up}

The experimental design to obtain the equations was conducted in the facilities of the company Pesquerías Isla Mayor S.A. (PIMSA, Spain), specifically in one of the tanks of the fattening room in its hatchery facilities. The experimental tank was a rectangular pool $(2 \times 8 \times 2 \mathrm{~m})$. A calibration test was performed before the start of the experiment in order to ensure that there were no significant echo returns coming from the pool. The test entailed performing a horizontal calibration and collecting recordings from the calibration sphere, which was a $13.7 \mathrm{~mm}$ copper sphere $(\mathrm{TS}=-45 \mathrm{~dB}$ ) placed at seven different distances with respect to the transducer (meter by meter, from 1 to $7 \mathrm{~m}$ away from the transducer). The mean deviation in the expected TS was lower than $0.6 \mathrm{~dB}$ at every distance.

TS data was recorded with a Simrad EK60 scientific echosounder (Simrad Kongsberg Maritime AS, Horten, Norway) equipped with a $200 \mathrm{kHz}$ circular split-beam transducer (ES200-7C). The transducer was placed on a stainless-steel clamping frame on one side of the pool. It was aimed horizontally, parallel to the water surface (Fig.1). The acoustic axis was located $1 \mathrm{~m}$ from the surface. The acoustic unit was calibrated with the calibration copper sphere according to the standard calibration method (Simrad, 2004). Echosounder settings are listed in Table 1.

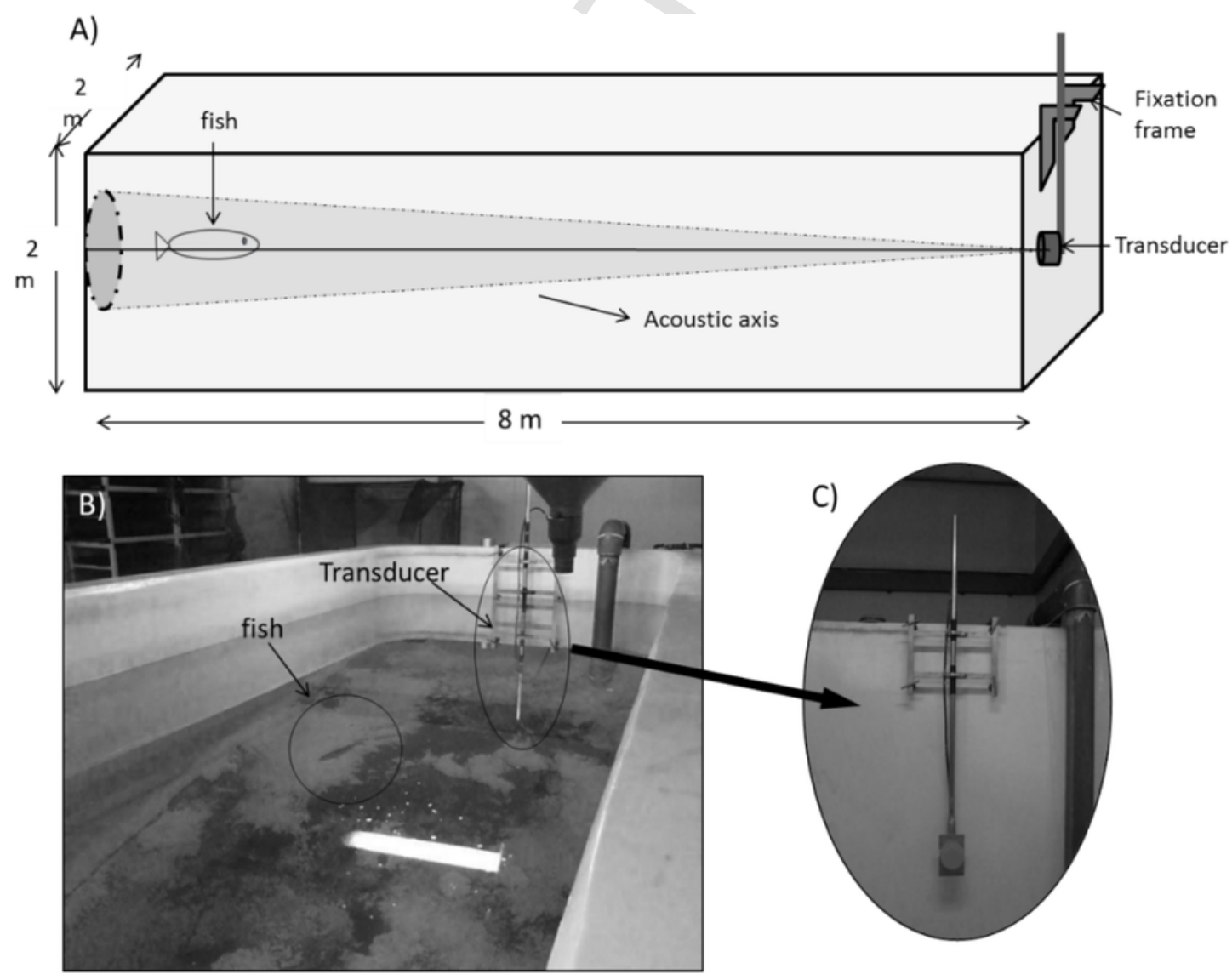

Fig. 1. A) Diagram of the experiment. B) Photograph of the experiment C) Photograph of the tranducer's frame. 
Table 1

Settings of the echosounder used to measure horizontal target strength (TS).

\begin{tabular}{ll}
\hline Parameters & \\
\hline Type of transducer & Simrad ES200-7C \\
Transducer shape & Circular \\
Transmission frequency $(\mathrm{kHz})$ & 200 \\
Transmitting power $(\mathrm{W})$ & 150 \\
Pulse length (ms) & 0.128 \\
Ping rate (ping•- ${ }^{-1}$ ) & 10 \\
Minimum threshold $(\mathrm{dB})$ & -70 \\
\hline
\end{tabular}

The sound records of a total of 15 individual sea bass and 15 individual gilt-head bream of different sizes. All selected fish were measured $(\mathrm{mm})$ in total, fork and standard length and weighed $(\mathrm{g})$ before being placed in the experimental pool. The different sizes were classified based on an artificial order depending on the weight range of the fish (Table 2).

Fish were individually placed in the tank to be insonified. Data was stored on a PC and later processed with the Sonar5 Prov.6.0.1 analysis software (Balk and Lindem, 2011). Raw data (.raw) was converted with the $40 \log$ R function. The echosounder's single echo parameters were set so that we obtained as many echoes as possible from the recorded fish. The minimum threshold was set to $-60 \mathrm{~dB}$; minimum and maximum echo durations were $0.80 \mathrm{~ms}$ and $1.6 \mathrm{~ms}$ (rel. to pulse lengths). The maximum gain compensation was $-3 \mathrm{~dB}$ (one-way) and the maximum phase deviation was 5 . TS values compensated for angular location in the beam (TS, dB re $1 \mathrm{~m}^{2}$ ) were used for the analysis. Once the echograms were obtained, insonified fish's tracks were manually classified and registered. The near field of the largest fish was calculated following the equation $D=r^{2} / \lambda$, where $r$ is the half length of the fish (SL) and $\lambda$ is the length of the sound wave (Medwin and Clay, 1998). Tracks were stored at a distance of $3.5-7 \mathrm{~m}$ from the transducer, avoiding the possible TS deviation caused by the effect of the near field of the fish and the transducer (Tichy et al., 2003; Dawson et al., 2000; Rodríguez-Sánchez et al., 2016). Only linear swimming tracks with at least five echoes were stored. Linear tracks are defined as the group of echoes drawn by the line described by a fish moving without changing its swimming direction (Fig. 2).

A total of 300 linear tracks were classified for each fish, i.e. 100 tracks for each main orientation. Following the methodology used in Rodríguez-Sánchez et al., 2015, the angles between $180^{\circ}$ to $360^{\circ}$ were converted to their specular angles, i.e. angles of $120^{\circ}$ were equal to angles of $90^{\circ}$. Only the swimming tilt of fish was considered, not its swimming direction. For each fish, the selected tracks were divided into 18 categories of $10^{\circ}$ according to their aspect angle $\left(0-180^{\circ}\right)$. Subsequently, the mean TS of each category was calculated and used for the creation of the equations. Three angular regions were established to describe swimming orientation: head and tail orientation (H\&T) (with angles between 0 and $20^{\circ}$ and $160-180^{\circ}$ ), oblique orientation (with angles between 20 and $70^{\circ}$ and $110-160^{\circ}$ ) and lateral orientation $\left(70-110^{\circ}\right)$.

Fish were anaesthetised with clove oil (García-Gómez et al., 2002) and laterally X-rayed after the sound measurements. Since not all insonified fish preserved their swim bladders in optimal conditions, the radiographic information was completed with several not insonified individual fish which belonged to the same fish farm. A portable Diagnostic X-ray Unit, EcoRayOrange $1060 \mathrm{HP}$, was used to perform the radiographs at an intensity of $4 \mathrm{mAs}$ and $55 \mathrm{kv}$ during $1.2 \mathrm{~s}$. the lateral area of the swim bladder (A) and the lateral area of the body (B) for each fish was calculated using the public domain Java image processing and analysis program IJ 1.46r (Rasband, 1997-2014) (Fig. 3). The lateral area of the fish was considered to be only from the mouth to the root of the tail (standard length) because the fish tail scatters sound very weakly (Kubilius and Ona, 2012).

Table 2

Spaurus aurata and Dicentrarchus labrax size classification.

\begin{tabular}{|c|c|c|c|c|c|c|c|c|c|c|c|c|}
\hline \multirow[b]{2}{*}{ Size class } & \multirow[b]{2}{*}{ Range (g) } & \multicolumn{6}{|c|}{ Spaurus aurata } & \multicolumn{5}{|c|}{ Dicentrarchus labrax } \\
\hline & & SL & S.D. & W & S.D. & $\mathrm{N}$ & Range (g) & SL & S.D. & $\mathrm{W}$ & S.D. & $\mathrm{N}$ \\
\hline 1 & $0-60$ & 127.5 & 2.8 & 50.0 & 10.7 & 3 & $0-50$ & 137.6 & 6.0 & 49.3 & 8.3 & 3 \\
\hline 2 & $100-150$ & 161.0 & 5.3 & 112.0 & 2.1 & 3 & $50-120$ & 168.0 & 3.6 & 90.6 & 1.1 & 3 \\
\hline 3 & $150-200$ & 172.3 & 8.7 & 171.5 & 6.5 & 3 & $120-200$ & 195.0 & 5.0 & 150.3 & 0.5 & 3 \\
\hline 4 & $500-700$ & 255.0 & 7.1 & 573.0 & 63.3 & 3 & $600-750$ & 340.0 & 10.0 & 699.3 & 37.1 & 3 \\
\hline 5 & $700-900$ & 286.6 & 10.4 & 778.0 & 75.9 & 3 & $750-950$ & 371.6 & 2.8 & 906.0 & 25.1 & 3 \\
\hline
\end{tabular}

SL Standard length (mm); W, weight (g); S.D., Standard deviation; N, number of individuals

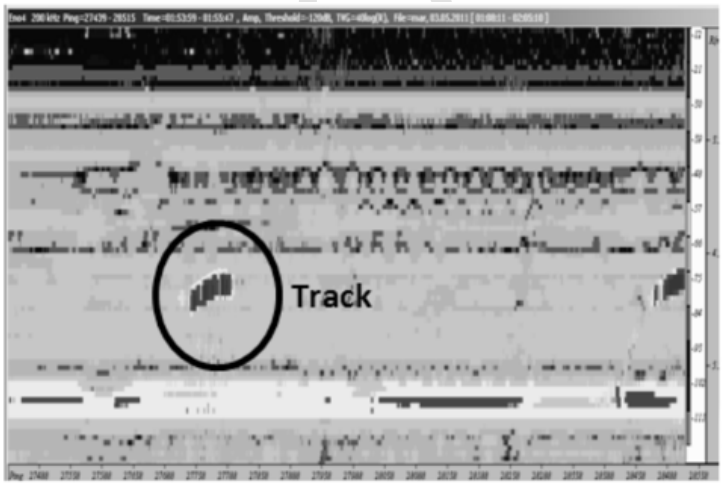

Alo(deg)
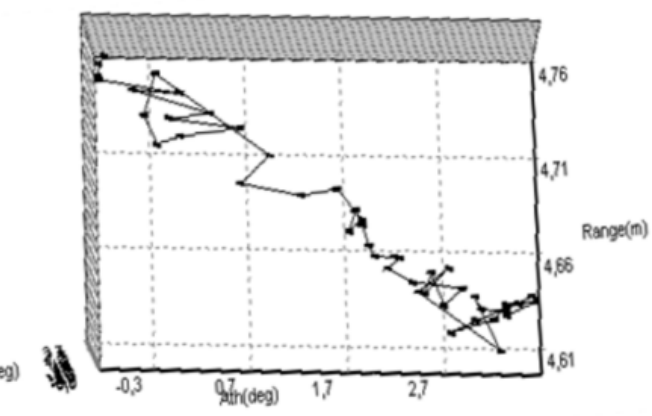

Track view in $\mathrm{XZ}$ axis

Fig. 2. Linear track. 

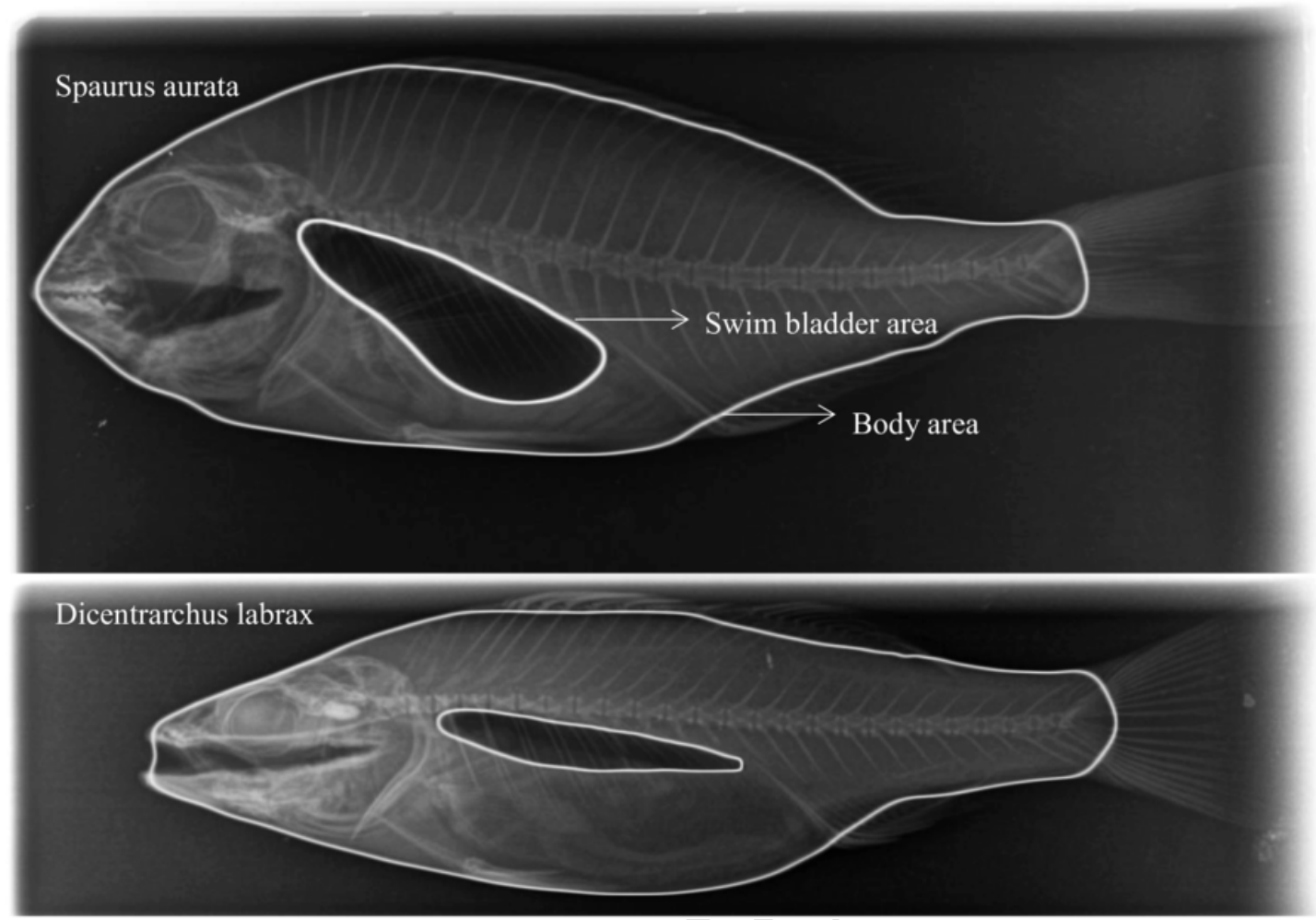

Fig. 3. Radiographs of two individuals of Spaurus aurata and Dicentrarchus labrax (size class 3) used in this study. The swim bladder area and the body area are highlighted.

\subsection{Statistical analysis}

The acoustic data collected was statistically analyzed by SPSS 20.0. (IBM Corp., 2011). A Kolmogorov-Smirnov goodness-of-fit test was used to test the normality of the TS values by species, orientation and size classes. For each species and orientation, the mean TS values calculated for each $10^{\circ}$-category were regressed against the logarithm of the standard length and weight of the individual fish using the following relationship:

1) $Y=a \cdot \log X+b$,

where $Y$ is the target strength (TS) in $\mathrm{dB}, X$ is the length or weight of the fish and $a$ and $b$ are regression constants.

Then, the specific equation for sea bass (species 1) and gilt-head bream (species 2) were calculated:

$T S_{1}=a_{1} \cdot \log X+b_{1}$

$T S_{2}=a_{2} \cdot \log X+b_{2}$

By definition:

TS $=10 \bullet \log \sigma$ and, $\sigma=10^{T S / 10}$.

Then, the TS mixed values $(\mathrm{dB})$ were calculated following the next formula:

$$
\begin{aligned}
\mathrm{TS}_{\text {mixed }} & =\mathrm{TS}_{\alpha_{1}, \alpha_{2}} \\
& =10 \cdot \log \left[\alpha_{1} \cdot 10^{\frac{T S_{1}}{10}}+\alpha_{2} \cdot 10^{\frac{T S_{2}}{10}}\right] \quad ; \quad 0 \\
& \leq \alpha_{i} \\
& \leq 1
\end{aligned}
$$

where $T S_{1}$ and $T S_{2}$ are the TS values derived from the species-specific equations and $\alpha_{1}$ and $\alpha_{2}$ are the distribution percentages of each species in a system. In this study, the mixed equation was calculated considering that the species were equally distributed, i.e. $50 \%$ of fish were sea-bass and $50 \%$ of fish were gilt-head beam.

The calculated $\mathrm{TS}_{\text {mixed }}$ values were used to create the mixed equation using formula 1).

An analysis of variance (ANOVA) was conducted for each studied species in order to test the TS differences in relation to the individuals' lengths. In order to study the variation of TS depending on the orientation, a one-way analysis of covariance (ANCOVA, $\alpha=0.05$ ) was conducted with the standard length as the covariate. In order to study the variation of the swim bladder area depending on the species and size class, a one-way analysis of covariance (ANCOVA, $\alpha=0.05$ ) was conducted using the body area as the covariate.

\section{Results}

TS data for each species, orientations and size class followed a normal distribution (Kolmogorov-Smirnov test, $p>0.05$ ). Fig. 4 shows the TS returned by sea bass of three size classes in each of the main orientations. As can be seen, TS values increase as fish become bigger. This TS-size correlation has proven to be a direct one both for sea bass (ANOVA, $\mathrm{F}_{14,1325}=23.230 ; p<0.001$ ) and gilt-head bream (ANOVA, $\left.\mathrm{F}_{14,1298}=10.019 ; p<0.001\right)$. Furthermore, we can see that TS values vary depending on the studied orientation. These variations occur both in sea bass (ANCOVA, $\mathrm{F}_{2,1137}=127.351 ; p<0.001$ ) and gilt-head bream (ANCOVA, $\mathrm{F}_{2,1253}=69.061 ; p<0.001$ ). In both species, head-tail orientations produce the lowest TS values $(-46.81 \mathrm{~dB}$, Std. E. 0.79 for sea bass and $-43.63 \mathrm{~dB}$, Std.E. 0.60 for gilt-head bream) and lateral orientations give the highest ones $(-39.50 \mathrm{~dB}$, Std.E. 0.95 for sea bass and $-38.66 \mathrm{~dB}$, Std.E. 1.93 for gilt-head bream).

Table 3 shows the results of the regressions of horizontal conversion TS-standard length and weight for each of the main orientations in sea 


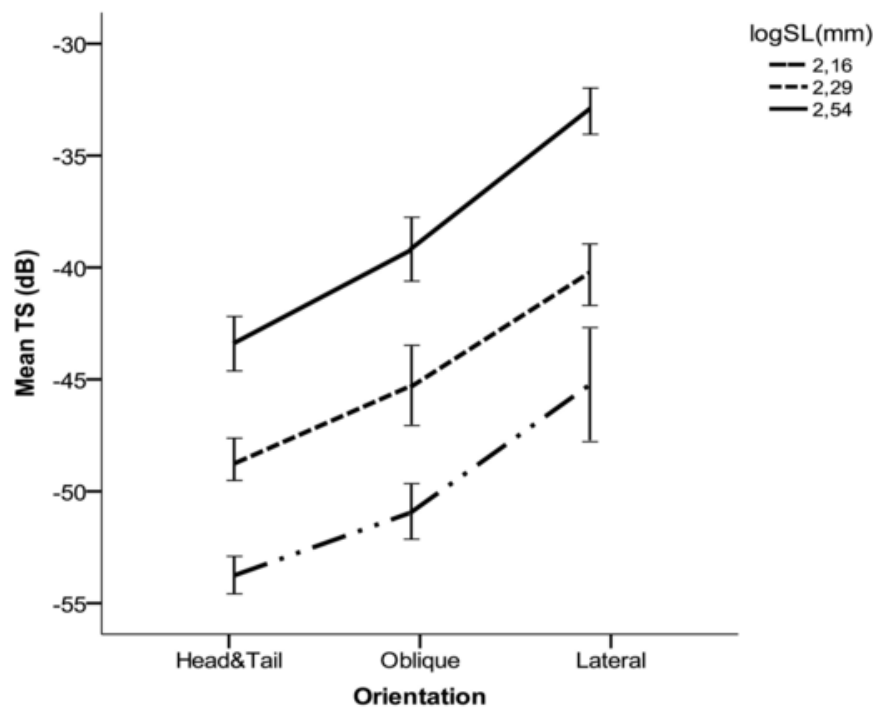

Fig. 4. Results of mean TS by orientation obtained after insonifying three sea bass of different sizes.

bass and gilt-head bream derived from acoustic data. Table 4 presents the results of the regressions of horizontal conversion TS-length and weight for the pool of species sea bass-gilt-head bream mixed at a ratio of $50 \%$ derived from the mixed equation. All regressions are meaningful $(p<0,001)$ and present a positive correlation between the acoustic signal increase and fish length. The equations obtained present a good adjustment for all studied orientations.

Fig. 5 represents TS-length lateral conversion equations for sea bass (solid line), gilt-head bream (dashed line) and the calculated mixed equation at a ratio of $50 \%$ (dashed grey line). As can be seen, the length estimated from each equation is different even though the TS is the same. If the conversion equation for sea bass is used, a TS value of $-35 \mathrm{~dB}$ corresponds to a sea bass of $275 \mathrm{~mm}$. Contrastingly, if the conversion equation for gilt-head bream is used, the same TS value of $-35 \mathrm{~dB}$ corresponds to a gilt-head bream of $250 \mathrm{~mm}$. The mixed equation at $50 \%$ falls in the middle of those two. Besides that, we can see that the equations of sea bass and gilt-head bream do not present the same slopes and the regressions intersect at one point. In lengths smaller than $225 \mathrm{~mm}$, gilt-head breams present a weaker TS than that of the sea bass. In longer lengths (corresponding to a TS of $-38 \mathrm{~dB}$ ), gilt-head breams present higher TS values.

Table 5 presents the measurements of the lateral swim bladder area and the lateral body area calculated from the radiographs conducted on the studied species. In both species, the area occupied by the gaseous swim bladder becomes more and more important as the size of the fish increases. The results of the ANCOVA performed on the swim bladder area data using the body area as the covariate prove the existence of a significant interaction between the species and size class factors $\left(\mathrm{F}_{4,35}=9.304 ; p<0.001\right)$. The lateral swim bladder area was different between the studied species for the size class 2 and 5 $\left(\mathrm{F}_{1,35}=12.268 ; p<0.001\right.$ for size class 2 and $\mathrm{F}_{1,35}=34.723 ; p<0.001$ for size class 5 ). In both cases, the swim bladder areas of gilt-head bream were bigger than these calculated for sea bass. No significant differences were found for the rest of size classes.

\section{Discussion}

Numerous studies have proved that the TS returned by fish is directly related to their length and weight. This allows us to use hydroacoustic devices to discover the number of fish and estimate their size and biomass in the studied aquatic systems (Love, 1977; Kubecka and Duncan, 1998; Lilja et al., 2000, Simmonds and MacLennan, 2005; among others). However, establishing TS-length or TS-weight conversion equations for the studied species is not easy. Having an appropriate and simple system to obtain data would greatly ease this task. In this sense, the setup conducted in this experiment is recommended because, on the one hand, it simplifies data acquisition and, on the other hand, the data quality is high enough to create conversion equations.

Previous studies where horizontal hydroacoustic techniques were applied have proved that TS varies depending on the fish's swimming orientation. These studies demonstrate that it is necessary to establish conversion equations where each one of the main orientations is separately considered (Ona, 1990; Simmonds and MacLennan, 2005; Jech, 2011). In our study, we can see that TS variations based on orientation are indeed meaningful. In order to obtain accurate results in TS-length or weight conversions, equations must be conducted for each one of the main orientations as the more accurate we are when converting TS to length or weight, the better quality our results will have.

Fig. 5 shows lateral conversion equations for each studied species, as it is shown length values vary depending on the conversion equation that is used even if the TS is the same. Sea bass' and gilt-head bream's regressions present a behavior adjusted to the typical growth of each species. Sea bass' growth tends to be isometric during its whole life. However, although gilt-head bream presents a similar growth at the beginning of its life, it presents a more allometric growth once it reaches a certain length. These differences in growth are reflected in the variations that we find in the slopes of the regression models for both species. Furthermore, these differences in the slopes of the line presented by both studied species also match the results of the lateral area occupied by the swim bladder in relation to the lateral body area of the fish. Previous studies highlight the important role that the swim bladder plays in the fish's response to sound. It is estimated that $95 \%$ of a fish's response to sound depends on its swim bladder (Foote, 1980;

Table 3

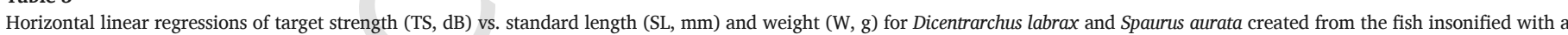
split-beam systems operating at $200 \mathrm{kHz}$.

\begin{tabular}{|c|c|c|c|c|c|c|c|c|}
\hline & Orientation & Variable & $a$ & Std.E. & $b$ & Std.E. & $R^{2}$ & $p$ \\
\hline \multirow[t]{6}{*}{ Dicentrarchus labrax } & $\mathrm{H} / \mathrm{T}$ & SL & 26.96 & 2.12 & -111.42 & 5.05 & 0.834 & $<0.001$ \\
\hline & Oblique & SL & 29.22 & 2.08 & -111.69 & 4.9 & 0.719 & $<0.001$ \\
\hline & Lateral & SL & 27.10 & 1.49 & -101.23 & 3.61 & 0.926 & $<0.001$ \\
\hline & $\mathrm{H} / \mathrm{T}$ & $\mathrm{W}$ & 8.83 & 0.65 & -68.33 & 1.57 & 0.851 & $<0.001$ \\
\hline & Oblique & $\mathrm{W}$ & 9.93 & 0.68 & -65.94 & 1.66 & 0.734 & $<0.001$ \\
\hline & Lateral & $\mathrm{W}$ & 9.27 & 0.49 & -58.98 & 1.23 & 0.932 & $<0.001$ \\
\hline \multirow[t]{6}{*}{ Spaurus aurata } & $\mathrm{H} / \mathrm{T}$ & SL & 43.97 & 6.24 & -152.85 & 14.90 & 0.756 & $<0.001$ \\
\hline & Oblique & SL & 42.91 & 3.80 & -143.31 & 8.86 & 0.659 & $<0.001$ \\
\hline & Lateral & SL & 46.56 & 3.36 & -146.67 & 7.95 & 0.936 & $<0.001$ \\
\hline & $\mathrm{H} / \mathrm{T}$ & $\mathrm{W}$ & 15.51 & 2.12 & -89.75 & 5.74 & 0.769 & $<0.001$ \\
\hline & Oblique & W & 12.78 & 0.93 & -74.94 & 2.37 & 0.754 & $<0.001$ \\
\hline & Lateral & W & 15.02 & 0.73 & -75.83 & 1.93 & 0.970 & $<0.001$ \\
\hline
\end{tabular}


Table 4

Horizontal linear regressions of target strength (TS, dB) vs. standard length (SL, mm) and weight (W, g) derived from the species-specific conversion equations created for a pool of sea bass and gilthead bream mixed at a ratio of $50 \%$.

\begin{tabular}{lllll}
\hline & Orientation & Variable & $a$ & $b$ \\
\hline \multirow{2}{*}{ Mixed equation } & H/T & SL & 32.96 & -125.63 \\
& Oblique & SL & 35.50 & -125.75 \\
& Lateral & SL & 35.41 & -119.82 \\
& H/T & W & 10.11 & -73.26 \\
& Oblique & W & 10.94 & -69.31 \\
& Lateral & W & 10.95 & -64.22 \\
\hline
\end{tabular}

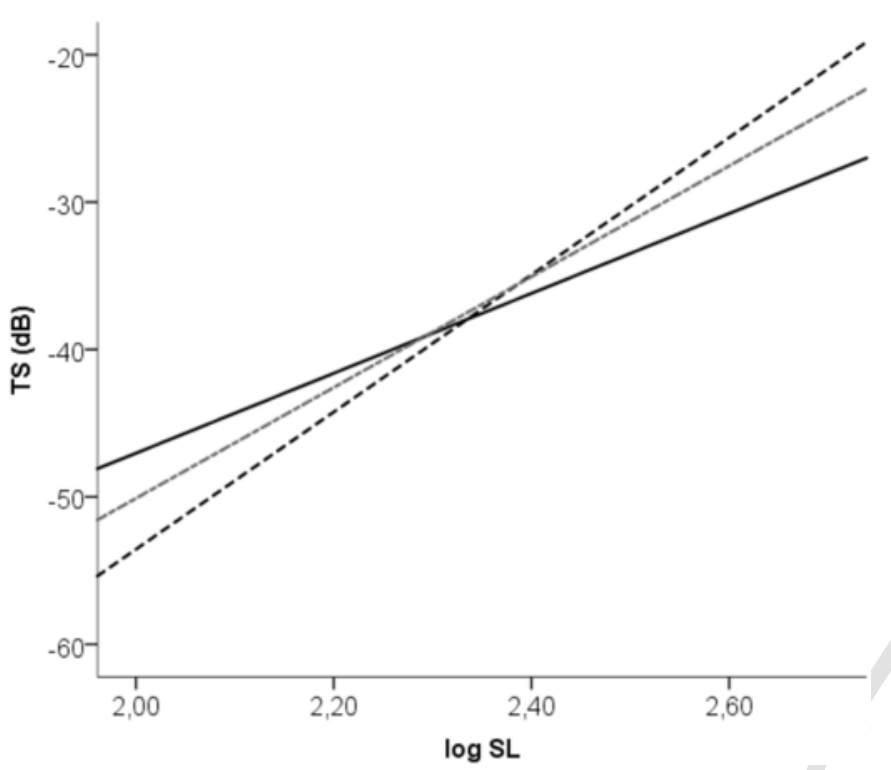

Fig. 5. Lateral regressions TS-length for Dicentrarchus labrax, Spaurus aurata and mixed equation.

Table 5

Measurements of body area and swim bladder area (Sb) in $\mathrm{cm}^{2}$ of the studied species classified by size class.

\begin{tabular}{clllll}
\hline $\begin{array}{c}\text { Size } \\
\text { class }\end{array}$ & $\mathrm{N}$ & $\begin{array}{l}\text { Body } \\
\text { area }\end{array}$ & $\begin{array}{l}\text { Std. } \\
\text { error }\end{array}$ & $\begin{array}{l}\text { Sb } \\
\text { area }\end{array}$ & $\begin{array}{l}\text { Std. } \\
\text { error }\end{array}$ \\
\hline Sea bass & & & & & \\
1 & 3 & 40,50 & 1,01 & 2,30 & 0,40 \\
2 & 3 & 64,54 & 3,00 & 2,93 & 0,02 \\
3 & 4 & 83,13 & 2,78 & 4,36 & 0,82 \\
4 & 4 & 212,81 & 10,39 & 15,28 & 1,65 \\
5 & 4 & 264,98 & 9,87 & 20,19 & 0,93 \\
Gilt-head bream & & & & & \\
1 & 4 & 49,25 & 14,26 & 2,67 & 0,28 \\
2 & 3 & 69,93 & 10,23 & 4,74 & 0,32 \\
3 & 5 & 110,89 & 19,76 & 5,16 & 0,41 \\
4 & 4 & 219,35 & 15,99 & 14,69 & 1,28 \\
5 & 4 & 262,67 & 15,38 & 23,76 & 1,70 \\
\hline
\end{tabular}

Hazen and Horne, 2003). If we have a look at the calculations of the area occupied by the swim bladder and the results of the comparison performed between species at different size classes, it becomes easier to understand this relation and how the changes in the swim bladder influence the fish's acoustic response. Taking this into account, we can see that the area occupied by the swim bladder for sea bass and gilt-head bream is similar at small sizes when their growth shows a similar behaviour. However, this changes from a particular size on, which leads to the intersection of the regression lines. Gilt-head bream is the species which presents the highest TS for the larger size classes. In any case, the equations developed for these species are different, but these comparisons help us understand the nature of the TS in relation to the fish's size and the importance of the swim bladder in the acoustic response.

Likewise, we can see how the mixed equation, which considers that each species makes up for $50 \%$ of the total, falls somewhere in between both species' specific relationships. This mixed equation will vary depending on the percentage of each species in the system, i.e. it will be more similar to the sea bass one when this species makes up for $>50 \%$ of the total and vice versa, and the differences will change the conversion results. Although the differences derived from using a conversion equation for species other than those studied might seem unimportant, these translate into relevant variations in biomass, particularly in species such as sea bass and gilt-head bream (an increase of $100 \mathrm{~mm}$ can be the equivalent of $300 \mathrm{~g}$ in sea bass and $>500$ in gilt-head bream). This proves that choosing the right TS-size conversion equation is crucial to accurately estimate fish's size and biomass (Boswell and Wilson, 2008; Boswell et al., 2008). Likewise, in mixed systems, applying a specific equation to the proportion of known species will undoubtedly improve the results of length and biomass derived from acoustic signals.

As proven by other previous studies (Kubecka and Duncan, 1998; Burwen and Fleischman, 1998; Frouzova et al., 2005; Lilja et al., 2000; Rodríguez-Sánchez et al., 2015), not only choosing the right equation can significantly influence the final result of the TS-size relation, but also choosing the right method to calculate the equation. This is particularly important in horizontal samplings because lateral detection implies a high loss of echoes coming from head/tail orientations and a higher variability in TS due to fish movement, etc. Therefore, a high-quality and specific conversion equation can compensate the defects produced in detections and also improve accuracy in biomass and density estimates.

Therefore, when performing hydroacoustic studies where fish's length and biomass estimations are important, the equations used must be specific to the studied species whenever possible. The TS-length relations developed in this study for Dicentrarchus labrax and Spaurus aurata using split-beam systems operating at $200 \mathrm{kHz}$ present a good adjustment and will allow us to calculate biomass of fish production systems where fish are bred. In addition, this study presents an equation that allows us to create our own mixed equation for those situations where more than one species is present. Based on specific equations, we will be able to easily create our own mixed equation adjusted to the percentages corresponding to each species in the system. As shown in this article, the studied species present differences in their acoustic response, which directly translates into variations in the estimated biomass. Therefore, this new equation will certainly improve biomass estimates in ponds with more than one species.

Applying hydroacoustic techniques to monitor size and quantity of fish in shallow semi-intensive production aquaculture ponds will allow us to obtain accurate estimates of fish biomass. In fact, the equations presented in this article have been used in the previously mentioned project (PI_57052) to calculate fish biomass in farming ponds with sea bass and gilt-head breams. The surveys conducted in this project have produced high-quality results valid to study the biomass of these two species in inland aquaculture ponds with semi-intensive production densities. These results indicate that the equations created in this study can be used in routine control studies in fish production companies providing us with quality results. This creates huge expectations regarding the future application and use of hydroacoustic techniques in the field of inland aquaculture farming management. 


\section{Acknowledgements}

This study's authors would like to thank the Superintendent of Economy and Knowledge (Andalusian Government) for the funding provided as part of the project (PI_57052) developed in collaboration with CTAQUA. We would like to thank the researchers Carlos Orduna Marín and Juan Ramón Cid Quintero for their selfless work to obtain the field data and to the company PIMSA for generously allowing us to use their facilities and fish. We would also like to thank the veterinarian JR Rodríguez for being kind enough to perform X-rays on the studied fish and Cristina Ocaña for her careful proofreading of the English text.

\section{References}

Apromar, 2016. La acuicultura en España. [online] Ministerio de Agricultura, Alimentación y Medioambiente. Available at: http://www.apromar.es, Accessed 20 April 2017.

Balk, H., Lindem, T., 2011. Sonar 4 and Sonar 5-Pro Post-Processing Systems, Operator Manual Version 6.0.2, 464 p, Lindem Data Acquisition Humleveien 4b.0870 Oslo, Norway.

Boswell, K.M., Wilson, C.A., 2008. Side-aspect target strength measurements of bay anchovy (Anchoa mitchilli) and Gulf menhaden (Brevoortia patronus) derived from ex situ experiments. ICES J. Mar. Sci. 65, 1012-1020.

Boswell, K.M., Kaller, M.D., Cowan Jr., J.H., Wilson, C.A., 2008. Evaluation of target strength-fish length equation choices for estimating estuarine fish biomass. Hydrobiologia 610, 113-123.

Burwen, D.L., Fleischman, S.J., 1998. Evaluation of side-aspect target strength and pulse duration as potential hydroacoustic discriminators of fish species in rivers. Can. J. Fish. Aquat. Sci. 55, 2492-2502.

Dawson, J.J., Wiggins, D., Degan, D., Geiger, H., Hart, D., Adams, B., 2000. Point-sourceviolations: split-beam tracking of fish at close range. Aquat. Living Resour. 13, 291-295.

Foote, K.G., 1980. Averaging of fish target strength functions. J. Acoust. Soc. Am. 67 (2), 504-515.

Frouzova, J., Kubecka, J., Balk, H., Frouz, J., 2005. Target strength of some European fish species and its dependence on fish body parameters. Fish. Res. 75, 86-96.

García-Gómez, A., de la Gándara, F., Raja, T., 2002. Utilización del aceite de clavo (Syzygium aromaticum L.) (Merr. \& Perry), como anestésico eficaz y económico para la- bores rutinarias de manipulación de peces marinos cultivados. Boletín del Instituto Español de Oceanografía 18 (1-4), 21-23.

Hazen, E.L., Horne, J.K., 2003. A method for evaluating the effects of biological factors on fish target strength. ICES J. Mar. Sci. 60, 555-562.

Henderson, M.J., Horne, J.K., Towler, R.H., 2007. The influence of beam position and swimming direction on fish target strength. ICES J. Mar. Sci. 65, 226-237.

IBM Corp, 2011. IBM SPSS Statistics for Windows, Version 20.0, Core Systems User's Guide. IBM Corp., Armonk, NY, (Released).

Jech, J.M., 2011. Interpretation of multi-frequency acoustic data: effects of fish orientation. J. Acoust. Soc. Am. 129 (1), 54-63.

Kubecka, J., Duncan, A., 1998. Acoustic size vs. real size relationships for common species of riverine fish. Fish. Res. 35, 115-125.

Kubečka, J., Hohausová, E., Matěna, J., Peterka, J., Amarasinghe, U.S., Bonar, S.A., Winfield, I.J., 2009. The true picture of a lake or reservoir fish stock: a review of needs and progress. Fish. Res. 96 (1), 1-5.

Kubilius, R., Ona, E., 2012. Target strength and tilt-angle distribution of lesser sandeel (Ammodytes marinus). ICES J. Mar. Sci. 69, 1099-1107.

Lilja, J., Marjomäki, T.J., Riikonen, R., Jurvelius, J., 2000. Side aspect target strength of Atlantic salmon (Salmo salar), brown trout (Salmo trutta), whitefish (Coregonus lavaretus) and pike (Esox lucius). Aquat. Living Resour. 13, 355-360.

Love, R.H., 1977. Target strength of an individual fish at any aspect. J. Acoust. Soc. Am. 62 (6), 1397-1403.

Lucas, M.C., Baras, E., 2000. Methods for studying spatial behaviour of freshwater fishes in the natural environment. Fish Fish. 1, 283-316.

Medwin, H., Clay, C.S., 1998. Fundamentals of Acoustical Oceanography. Academic Press, Boston, 712.

Ona, E., 1990. Physiological factors causing natural variations in acoustic target strength of fish. J. Mar. Biol. Ass. UK 70, 107-127.

Rasband, W.S., 1997-2014. ImageJ. U. S. National Institutes of Health, Bethesda, MD http: //imagej.nih.gov/ij/.

Rodríguez-Sánchez, V., Encina-Encina, L., Rodríguez-Ruiz, A., Sánchez-Carmona, R., 2015. Horizontal target strength of Luciobarbus sp. in ex situ experiments: testing differences by aspect angle, pulse length and beam position. Fish. Res. Vol. 164, 214-222.

Rodríguez-Sánchez, V., Encina-Encina, L., Rodríguez-Ruiz, A., Sánchez-Carmona, R., 2016. Do close range measurements affect the target strength (TS) of fish in horizontal beaming hydroacoustics?. Fish. Res. 173, 4-10.

Simmonds, D.M., MacLennan, E.J., 2005. Fisheries acoustics: theory and practice. In: Fish and Aquatic Resources Series, second ed., 10, Blackwell Science, Oxford.

Simrad, 2004. Operator Manual, Simrad EK60 Scientific Echosounder Application, Simrad AS, (ISBN 82-8066-011-9).

Soliveres, E., 2015. Estimación de biomasa de peces en granjas marinas mediante ultrasonidos. Masters Thesis. In: Universitat Politécnica de Valencia. Valencia, Spain.

Tichy, F.E., Solli, H., Klaveness, H., 2003. Non-linear effects in a $200-\mathrm{kHz}$ sound beamand the consequences for target-strength measurement. ICES J. Mar. Sci. 60, 571-574. 